\title{
Enhancement of the Solubility and Dissolution Rate of Rebamipide by Using Solid Dispersion Technique (Part I) Muna Y.Ismail", 1 and Mowafaq M. Ghareeb**
}

*College of Pharmacy, University of Uruk, Baghdad, Iraq

**Department of Pharmaceutics, College of Pharmacy, University of Baghdad, Baghdad, Iraq

\section{Abstract}

Solid dispersion is an attractive tool of pharmaceutical technology used to improve the physical properties of drugs, among these properties is the solubility of the drugs.

Rebamipide (REM) is used as potent antiulcer, mucoprotective drug, by stimulating the generation of prostoglandine enhanced mucosal protection. REM is a poorly soluble drug of class IV of biopharmaceutical classification system (BCS). In the present study, attempts were made to enhance solubility and dissolution rate of REM by solid dispersion technique.

Thirty six REM formulas were prepared as a solid dispersion using different polymers include pluronic F-127 (poloxamer 407), polyethylene glycol 6000 (PEG6000), polyvinylpyrrolidon (PVP K30), and D- $\alpha$-Tocopheryl polyethylene Glycol 1000 Succinate (TPGS) at different drug: polymer ratios (1:9, $1: 12$, and 1:15) by using different preparation methods include solvent evaporation, fusion, and kneading method. The prepared formulas were characterized regarding drug content, production yield, solubility study, dissolution study, FTIR, DSC, PXRD, and SEM.

The results indicate that the used polymer show improvement in drug solubility in the following descending order; TPGS>PVP K30>PEG $6000>$ pluronic F-127 and the best drug: polymer ratio was 1:15 while best method was solvent evaporation. The optimum formula composes of drug: TPGS at ratio of 1:15 prepared by solvent evaporation shows 36.4 folds solubility enhancement compared to pure REM. The advance characterization of the selected formula indicates amorphousization of drug.

It can be concluded that the solid dispersion technique is simple physical approach that can be followed to solve the problem of REM solubility using TPGS as hydrophilic carrier and best method is solvent evaporation method.

Keywords: Rebamipide , Solid dispersion, TPGS.
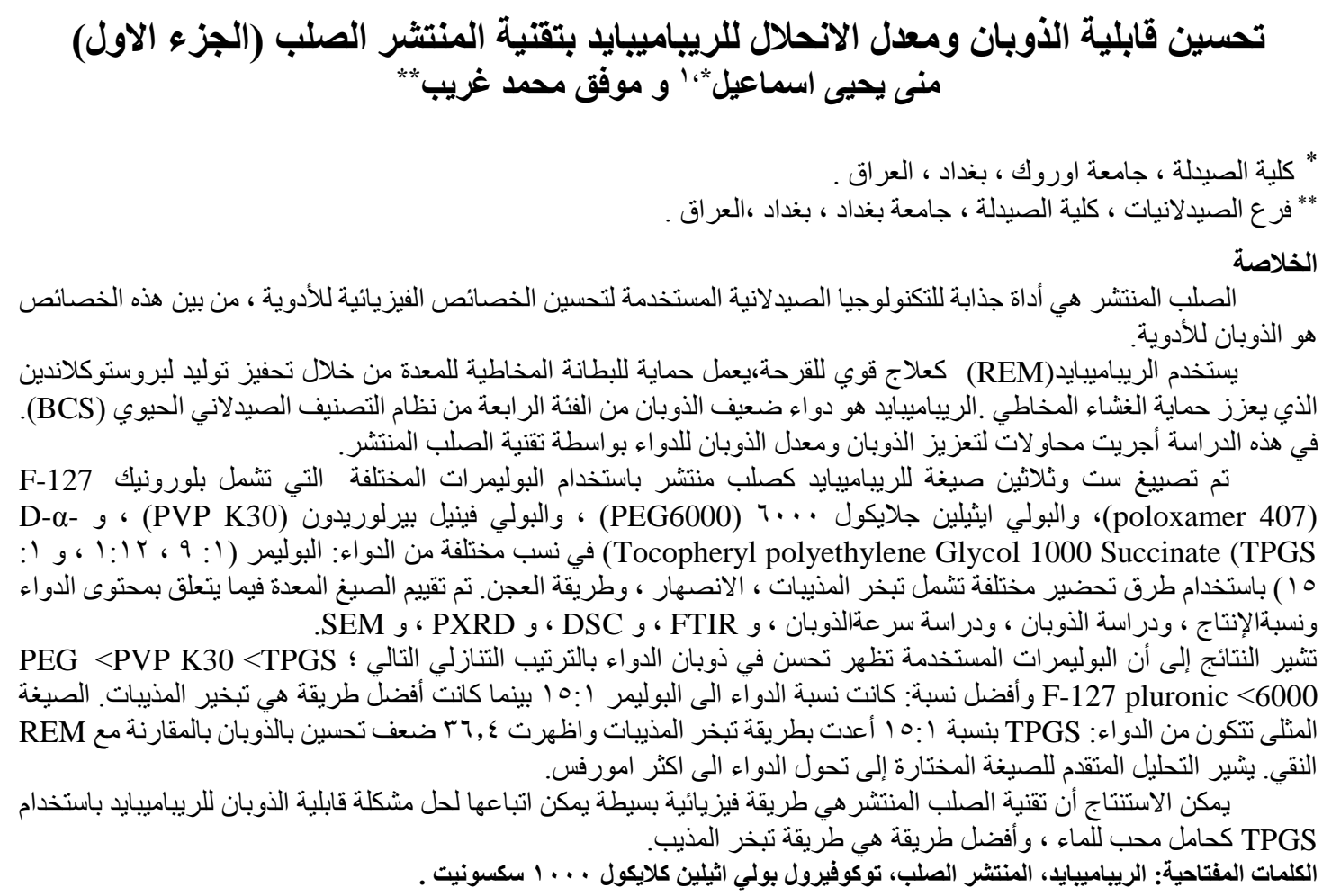

${ }^{1}$ Corresponding author E-mail: munayehia92@gmail.com

Received: 4/ 8 /2018

Accepted: 2 / $10 / 2018$

Iraqi Journal of Pharmaceutical Sciences 


\section{Introduction}

Rebamipide has a chemical formula of [2 - ( 4 - chlorobenzoylamino ) - 3- [ 2 ( 1H ) - Quinolinon - 4 - yl ] proponic acid], (REM) as shown in Figure (1). REM is an amino acid analog of $2(1 \mathrm{H})$ - Quinolinone. It is a new mucoprotactive drug which was developed in Japan for the treatment of peptic ulcer disease (PUD) ${ }^{(1)}$.<smiles>O=C(NC(Cc1cc(=O)[nH]c2ccccc12)C(=O)O)c1ccc(Cl)cc1</smiles>

Figure 1. The chemical structure of $\mathbf{R E M}^{(1)}$

Mechanisms for its therapeutic effect in PUD involves stimulating the generation of prostaglandins, enhanced mucosal protection, removal of oxygen free radicals and inhibiting the production of inflammatory cytokines ${ }^{(2)}$. Clinical investigations have shown that it has marked effects on ulcer healing and helicobacter pylori (HP) adhesion. Research has shown that the REM levels presented in the gastric mucosa and gastric mucus were a result of local penetration, and the local concentration allows it to exhibit a variety of antiulcer effects after oral administration $^{(3)}$.

REM is classified as a class IV based on the biopharmaceutical classification system, due to its low water solubility and permeability, the bioavailability of REM is under $10 \%$ in humans. To increase the low solubility of poor water soluble drug and improve its bioavailability, several strategies can be employed, such as size reduction, use of surfactants, $\mathrm{pH}$ adjustment, and complexation with cyclodextrines, emulsions and solid dispersion $^{(4)}$.

Solid dispersion technologies are used for improving oral absorption and bioavailability of BSC class II and IV drugs, in solid dispersion drug disperse in the matrix generally a hydrophobic drug is dispersed in a hydrophilic matrix, which forms a solid dispersion. When the solid dispersion interacts with gastrointestinal fluid, the carrier or polymer which enhances solubility of drug it first dissolves and the drug release as fine colloidal particles. This result in enhanced surface area produces higher dissolution rate and bioavailability of poor water soluble drug ${ }^{(5)}$. Many polymers have been used for SD, like pluronic F-127, polyethelen glycol (PEG), polyvinylpyrrolidon (PVP).

To enhance the solubility and then the dissolution of the drugs ${ }^{(6)}$.

\section{Materials and Methods \\ Materials}

Rebamipide was obtained from apopharm, China, Pluronic F-127 from sigma, USA, PEG 6000 from Chemifine chemicals. Mumbai, India , PVP K30 from Hyper Chem, China and (TPGS) from Hyper Chem, China , while methanol from Sigma-Aldrich Co., Germany. All other reagents were of analytical grade.

Preparation of REM- solid dispersionsolvent evaporation method

Rebamipide solid dispersion were prepeared by solvent evaporation method. Using different carriers (Pluronic F-127, PEG 6000 , PVP K30 and TPGS) in different ratios as shown in Table (1), the drug and carriers; were taken separately in different ratios(1:9,1:12and1:15) wt:wt and transferred in a beaker containing appropriate amounts of methanol (solvent).By using magnetic stirrer,then the two solutions was mixed together on magnetic stirrer. The solvent was removed by leaving it for $24 \mathrm{hr}$. at room temperature $\left(25-30{ }^{\circ} \mathrm{C}\right)$. The dried solidifing mass were scraped, crushed and grinded in mortar and pastle to pass through the sieve no 20 and strored in aglass umber container in a deiccator for subsequent study ${ }^{(7)}$.

\section{Fusion method}

In fusion method, accurate amount of carriers and drug in the different ratio $(1: 9,1: 12$, $1: 15)$. The carrier was first melted in Petri-dish at the melting point of each polymer and the drug was dispersed in the molten mixture with constant stirring then cooled it. The dried mass was crushed and grinded in mortar and pastle to pass through sieve no.20 and store in desiccator (8). A modification of the above method when used PVP K30, have been prepared by closed melting point method. This method includes the addition of water to the carrier and heated, the drug dispersed in the heated mixture with constant stirring then cooled it. The dried mass was crushed and grinded in mortar and pastle to pass through sieve no.20 and store in desiccator (9).

\section{Kneading method}

An accurate weighted quantity of drug and corresponding water soluble carrier (Table 1 ), are mixed together in glass mortar, and triturate for 30 minutes, with drop by drop distilled until get the structure paste, the paste was spread over suitable Petri-dish and dried in oven at $40^{\circ} \mathrm{C}$ for 24 hours. (Except in TPGS polymer, the temp. was $25^{\circ} \mathrm{C}$. The dried mass was crushed and grinded in mortar and pastle to pass through sieve no.20 and store in desiccator (10). 
Table 1. Composition of REM and carriers using solid dispersion method.

\begin{tabular}{|c|c|c|c|}
\hline Formulation code & Water soluble carriers & $\begin{array}{l}\text { Drug: carriers ratio } \\
\text { (wt:wt) }\end{array}$ & $\begin{array}{l}\text { Methods of } \\
\text { preparation }\end{array}$ \\
\hline SD 1 & Pluronic F-127 & $1: 9$ & Solvent evaporation \\
\hline SD 2 & & $1: 12$ & Solvent evaporation \\
\hline SD 3 & & $1: 15$ & Solvent evaporation \\
\hline SD 4 & & $1: 9$ & Fusion \\
\hline SD 5 & & $1: 12$ & Fusion \\
\hline SD 6 & & $1: 15$ & Fusion \\
\hline SD 7 & & $1: 9$ & Kneading \\
\hline SD 8 & & $1: 12$ & Kneading \\
\hline SD 9 & & $1: 15$ & Kneading \\
\hline SD 10 & PEG 6000 & $1: 9$ & Solvent evaporation \\
\hline SD 11 & & $1: 12$ & Solvent evaporation \\
\hline SD 12 & & $1: 15$ & Solvent evaporation \\
\hline SD 13 & & $1: 9$ & Fusion \\
\hline SD 14 & & $1: 12$ & Fusion \\
\hline SD 15 & & $1: 15$ & Fusion \\
\hline SD 16 & & $1: 9$ & Kneading \\
\hline SD 17 & & $1: 12$ & Kneading \\
\hline SD 18 & & $1: 15$ & Kneading \\
\hline SD 19 & PVP K 30 & $1: 9$ & Solvent evaporation \\
\hline SD 20 & & $1: 12$ & Solvent evaporation \\
\hline SD 21 & & $1: 15$ & Solvent evaporation \\
\hline SD 22 & & $1: 9$ & Fusion \\
\hline SD 23 & & $1: 12$ & Fusion \\
\hline SD 24 & & $1: 15$ & Fusion \\
\hline SD 25 & & $1: 9$ & Kneading \\
\hline SD 26 & & $1: 12$ & Kneading \\
\hline SD 27 & & $1: 15$ & Kneading \\
\hline SD 28 & TPGS & $1: 9$ & Solvent evaporation \\
\hline SD 29 & & $1: 12$ & Solvent evaporation \\
\hline SD 30 & & $1: 15$ & Solvent evaporation \\
\hline SD 31 & & $1: 9$ & Fusion \\
\hline SD 32 & & $1: 12$ & Fusion \\
\hline SD 33 & & $1: 15$ & Fusion \\
\hline SD 34 & & $1: 9$ & Kneading \\
\hline SD 35 & & $1: 12$ & Kneading \\
\hline SD 36 & & $1: 15$ & Kneading \\
\hline
\end{tabular}

Characterization of REM- solid dispersion Determination of percent production yield of prepared REM- solid dispersion

The percent of production yield (PY \%) of prepared REM - solid dispersion was determined by calculating the ratio of actual weight of the obtained solid dispersion on the theoretical weight of solid dispersion using the following equation ${ }^{(11)}$ :

$$
P Y \%=\frac{\text { Actual weight of solid dispersion }}{\begin{array}{l}
\text { Theoretical weight } \\
\text { of solid dispersion }
\end{array}} \times 100
$$

Solubility studies of REM solid dispersion

An excess amount of pure REM and prepared REM-solid dispersion were placed in contact with ten milliliters of water in closed tight container that shakes continually for $72 \mathrm{hr}$. in thermo- control water bath at $25^{\circ} \mathrm{C}$. After the removal from the shaker water bath, the tubes put in centrifuge for $10 \mathrm{~min}$ at $4000 \mathrm{rpm}$. The solutions were filtered through a $0.45 \mu \mathrm{m}$ filter membrane, and the concentration of REM was determined by UV - spectrophotometer at $\lambda \max .227 \mathrm{~nm}$ wavelength the study was done in triplicate $^{(12)}$. 


\section{Drug content analysis}

The REM solid dispersion equivalents to $100 \mathrm{mg}$ of rebamipid were taken and dissolved in $100 \mathrm{mls}$. of methanol, then filtered by using $0.45 \mu \mathrm{m}$ filter membrane. The filtrate was suitably diluted with methanol; the drug solution was analyzed by using UVspectrophotometer at $\lambda \max .227 \mathrm{~nm}$ wavelengths. The percentage of drug content in solid dispersion was calculated by using the following equation: ${ }^{(13)}$

$$
\text { Drug content } \%=\frac{\text { Actual weight of } R E M}{\begin{array}{c}
\text { Theoretical wieght } \\
\text { of } R E M
\end{array}} \times 100
$$

\section{In-vitro dissolution studies}

The in-vitro release of REM in the solid dispersion was determined and compared with pure REM drug by using USP XXII rotating paddle apparatus (II). REM-solid dispersion equivalents to $100 \mathrm{mg}$ of pure drug were dispersed in dissolution medium surface. The dissolution medium employed for drug release study was 900 milliliters. of $0.1 \mathrm{~N} \mathrm{HCl}$, maintained at $37.5 \pm 0.5^{\circ} \mathrm{C}$ by means of thermostatic water bath and under shaking provide by the paddle at $100 \mathrm{rpm}^{(14)}$.

Five milliliters were withdrawn at $(1,3,5,10,15,30,45,60,90,120)$ minutes time interval for two hours, and each withdrawn sample was replaced with an equal volume of fresh $0.1 \mathrm{~N} \mathrm{HCl}$ dissolution medium as soon as to maintain sink condition. The samples were filtered through $0.45 \mu \mathrm{m}$ filter membrane and analyzed by UV-spectrophotometer at $\lambda \max$ $227 \mathrm{~nm}$ wavelengths ${ }^{(15)}$.

\section{Factors affecting dissolution behavior of REM from solid dispersion}

The effect of different polymer types (Pluronic F-127, PEG 6000, PVP K30 and TPGS) on dissolution behavior of REM from solid dispersion was studies on the formulas SD1, SD10, SD19 and SD28.

The effect of different drug: polymer ratio on dissolution behavior of REM from solid dispersion was studies on the formulas (SD1SD3), (SD10-SD13), (SD19-21), (SD28SD30), which they are belong to the solvent evaporation method.

The effect of preparation method on dissolution behavior of REM from solid dispersion was studies on the formulas (SD1, SD4, SD7), (SD10, SD13, SD16), (SD19, SD22, SD25) and (SD28, SD31, SD34).

The solubility and in-vitro dissolution profile were used for selecting the best formula which will be subjected to further analysis.
Evaluations of selected solid dispersion formula

Fouier transforms infrared spectroscopy (FTIR)

The FTIR of pure REM and selected formula were performed to investigate drugpolymer the interaction. The samples were compressed with potassium bromide as a disc, and carried out by FTIR Shimadzu 8000 Japan; the scanning range the spectrum obtained was in between the wave number of 4000- $400 \mathrm{~cm}^{-1}$ (16).

Differential scanning calorimeter (DSC)

Thermal characteristic of the selected formula and TPGS characterized by an automatic thermal analyzer system (Shimadzu, DSC-60, Japan). Approximately $5 \mathrm{mg}$ of samples were placed in none hermetically aluminum pan and heated at rate $10^{\circ} \mathrm{C} / \mathrm{min}$ over temperature $25^{\circ} \mathrm{C}$ to $400^{\circ} \mathrm{C}^{(17)}$.

Powder $x$-ray diffraction (PXRD)

Powder x-ray diffraction is instrument used to study the molecular structure of crystalline substance such as drug and optimum formula. The degree of crysallinity was determined by (XRD-6000, Shimadzu, Japan $220 \mathrm{~V} / 50 \mathrm{~Hz}$ ).

X- Ray diffractometer with $\mathrm{Cu}-\mathrm{Ka}$ radiation at $40 \mathrm{Kv}$ and $30 \mathrm{~mA}$. Samples were scanned over a $2 \theta$ range of $30-80^{\circ}$ at step size of $0.02^{\circ}(18)$

\section{Scanning electron microscopy (SEM)}

Scanning electron microscope of the selected formula and pure drug (REM) were analyzed using (Shimadzu, Japan); in order to examination the external morphology and shape of the particle. The samples coated with layer of gold at room temperature under Argon gas. The SEM was operated at a high vacuum with accelerating voltage of 5-15 KV. Secondary electron images were recorded digitally at higher magnification ${ }^{(19)}$.

\section{Statistical Analysis}

The results of the experiments were given as a mean for triplicates samples \pm stander deviation and were analyzed according to oneway analysis of variance (ANOVA) test level of $(\mathrm{P}<0.05)$ was considered to be statistically significant, and non-significant value with $(\mathrm{P}>0.05)$.

\section{Results and Disscution}

Determination of REM saturated solubility

The solubility of REM in different media (water, $0.1 \mathrm{~N} \mathrm{HCl}$, phosphate buffer $\mathrm{pH}$ 6.8) at $25{ }^{\circ} \mathrm{C}$ was determined. The results revealed that the solubility of REM is very poor in $0.1 \mathrm{~N} \mathrm{HCl}$ $\mathrm{pH}$ (1.2), which may be attributed to it is acidic nature of the drug, so increasing the $\mathrm{pH}$ of the solvent using phosphate buffer lead to increase 
the solubility from $1.8 \mu \mathrm{g} / \mathrm{ml}(\mathrm{pH} 1.2)$ to 1320 $\mu \mathrm{g} / \mathrm{ml}$ at pH6.8 (730 $\mathrm{x}$ fold). And the solubility of REM in water was $23.9 \mu \mathrm{g} / \mathrm{ml}$ as shown in Table (2).

Table 2. Saturation solubility of REM in different media at $25^{\circ} \mathrm{c}$ under normal atmospheric pressure.

\begin{tabular}{|l|l|l||}
\hline Solvent & $\begin{array}{l}\text { Solubility } \\
(\mu \mathrm{g} / \mathrm{ml}) \\
\text { mean } \pm \mathrm{SD}^{*}\end{array}$ & $\begin{array}{l}\text { Description } \\
\text { forms }\end{array}$ \\
\hline $\begin{array}{l}\text { Distilled } \\
\text { water }\end{array}$ & $23.9 \pm 0.1$ & $\begin{array}{l}\text { Practically } \\
\text { insoluble }\end{array}$ \\
\hline $0.1 \mathrm{~N} \mathrm{HCl}$ & $1.8 \pm 0.1$ & $\begin{array}{l}\text { Practically } \\
\text { insoluble }\end{array}$ \\
\hline $\begin{array}{l}\text { Phosphate } \\
\text { buffer 6.8 }\end{array}$ & $1320 \pm 1.15$ & $\begin{array}{l}\text { Slightly } \\
\text { soluble }\end{array}$ \\
\hline
\end{tabular}

*SD stander deviation from mean, $\mathrm{n}=3$

On the other hand, the solubility of REM at phosphate buffer pH6.8 $(1320 \mu \mathrm{g} / \mathrm{ml})$ is still with a range of slightly soluble drug category. That it's why the mission of the study; to enhance the solubility of REM .

Characterization of REM - solid dispersion Determination of percent production yield of prepared REM-solid dispersion

The REM yield percentage was calculated to investigate best method of preparation of solid dispersion granules after drying, grinding and sieved through mesh size no. 20 .

The solid dispersion granules were valid with percentage yield 76- 99\%, mainly for solvents and fusion methods.

This behavior may be attributed to the best entrapment or best solvation of REM particles by polymer used using melted carriers (fusion), or solvent vehicle (evaporation) methods.

\section{Determination of REM content in prepared solid dispersion}

Moreover the content of REM in solid dispersion was found in a range of $96.12 \%$ $100.2 \%$ in all prepared formulations, which is in the same range of U.S. Pharmacopoeia requirements $(90-110 \%)$

The above results indicated a uniform distribution of REM particles within polymers used in all prepared formulas ${ }^{(20)}$.

\footnotetext{
Determination of saturated solubility of REM in solid dispersion

The solubility study of REM as a pure powder and as a drug loaded in solid dispersion formulas was carried out using distillated water maintained at $25^{\circ} \mathrm{C}$ temperature. Figure (2), (3) and (4) demonstrated that best result obtained, when TPGS used as a solid dispersion carriers compared with PVP K30, PEG 6000 and
}

pluronic F-127 polymers the saturated solubility were $874.6 \mu \mathrm{g} / \mathrm{ml}, 180.1 \mu \mathrm{g} / \mathrm{ml}$, $59.6 \mu \mathrm{g} / \mathrm{ml}$, and $61.7 \mu \mathrm{g} / \mathrm{ml}$., respectively using (1:15) drug polymer ratios, compared with 23.9 $\mu \mathrm{g} / \mathrm{ml}$ for pure REM powder

The last behavior of above polymers is significant $(p<0.05)$, and increasing the solubility of REM may be referred to hydrophilic nature of all polymer used, besides hydrogen bonding formation between REM and carrier polymers to enhance the solubility ${ }^{(21)}$.

On the other hand, TPGS was found as the best polymer carriers for REM with enhanced saturated solubility by $36.4 \mathrm{x}$ fold compared with a pure REM.

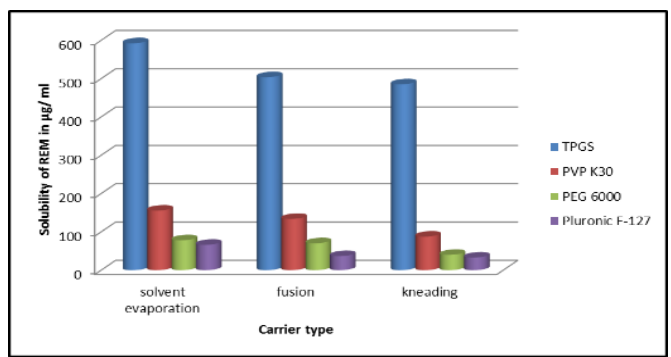

Figure 2. Effect of carrier type of REM solid dispersion at ratio $(1: 9)$ on the solubility of REM in distilled water at $25^{\circ} \mathrm{c}$ (results are expressed as mean, $n=3$ )

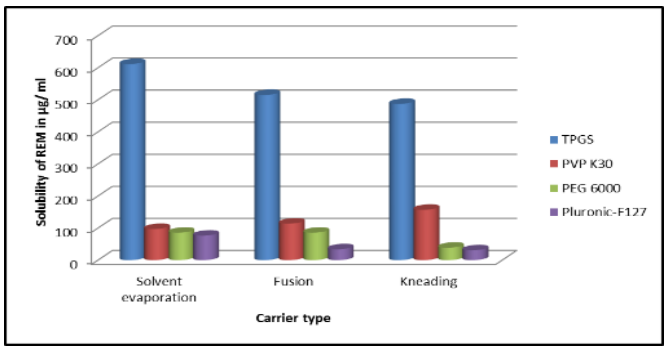

Figure 3. Effect of carrier type of REM solid dispersion at a ratio $(1: 12)$ on the solubility of REM in distilled water at $25^{\circ} \mathrm{c}$ (results are expressed as mean, $n=3$ ).

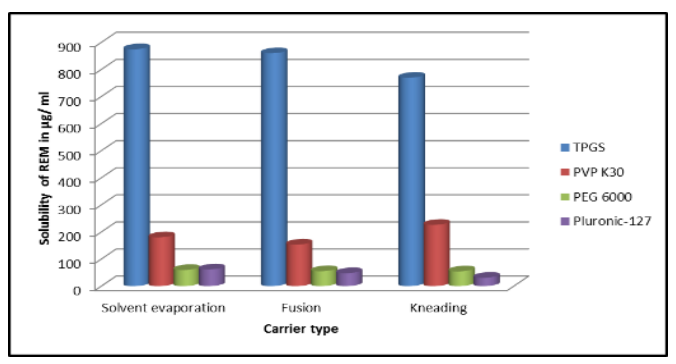

Figure 4. effect of carrier type of REM solid dispersion at a ratio $(1: 15)$ on the solubility of REM in distilled water at $25^{\circ} \mathrm{C}$ (results are expressed as mean, $n=3$ ). 
Factors affecting dissolution of REM within solid dispersion particles

Effect of polymer type

Figure (5) demonstrated that best results obtained for REM dissolution when TPGS polymer used among other hydrophilic polymers.

REM: polymer ratio (1:12) using solvent evaporation method demonstrated, that $70 \%$ of REM released in aqueous medium $(\mathrm{p}<0.05)$ was increased compared with $14 \%$, $4 \%$, and $2 \%$ for PVP k30, PEG6000 and pluronic F-127 polymers, respectively after 90 minutes.

This result was attributed to that TPGS has amphiphilic structure of lipophilic alkyl tail and hydrophilic polar head that lowering surface tension between REM and solvent, improvement of wetting characteristics and micellar solubilization of drugs ${ }^{(22)}$.

In a focus of using surfactants like TPGS, the surface activity and self-emulsifing properties was gave the third generation type solid dispersion that's have highest degree of solubilization together with improving drug wet ability and spread ability by decreasing the interfacial tension between the drug particles and the aqueous medium, and also the amorphization of the crystalline drugs and avoiding recrystallization that can occur after contact with aqueous medium can further enhances the saturation solubility ${ }^{(23)}$.

Meanwhile, the dissolution profile for REM-PVP K30 solid dispersion (SD19) had maximum percentage of $15.1 \%$ within 120 minutes, although PVP K30 inhibits crystal formation of drugs and resulting amorphous nature of drug in the solid dispersion and enhance the solubility of REM, but still lower than that of TPGS use ${ }^{(24)}$.

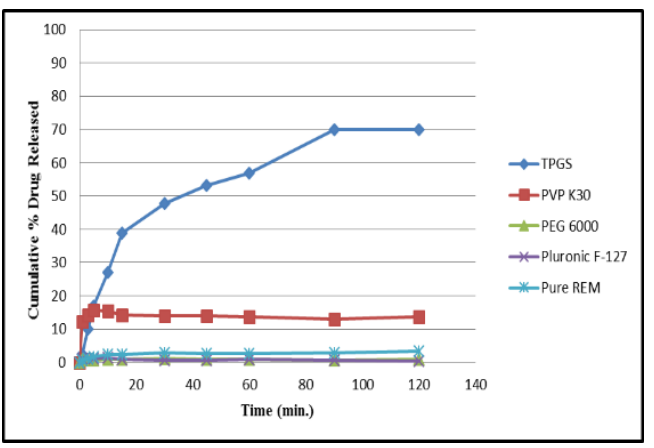

Figure 5. Effect of polymer type of rem- solid dispersion prepared by solvent evaporation method with drug: polymer ratio $1: 12$ on the release profile of rem in $0.1 \quad \mathrm{NCl}$ dissolution medium at $37^{\circ} \mathrm{c}$ (results are expressed as mean, $n=3$ ).

\section{Effect of carrier ratio}

The effect of different drug: polymer ratio on the dissolution behavior of REM solid dispersion was studied, as shown in Figure (6).

The figure represents the percent release profile of REM from solid dispersion of TPGS that prepared by solvent evaporation method. It was observed that as the ratio of TPGS increased in formulas (SD28-SD30), the drug release from solid dispersion was increased significantly $(\mathrm{P}<0.05)$. Formula SD30 appeared to have the highest the cumulative percent of REM release of $100 \%$ comparing to SD 29 of $47.8 \%$ and SD28 of $35.3 \%$ after 30 minutes.

The solid dispersions prepared with higher ratios of hydrophilic polymer could be offer more available space for surrounding of hydrophobic REM particle resulted in rapid hydration of drug molecules and consequently better wet ability and enhancement in the dissolution.

This may be attributed to TPGS melts and dissolves in the dissolution medium of $37^{\circ}$ Cquickly and acts as an emulsifier of hydrophobic drugs ${ }^{(25)}$.

Moreover, the transformation of crystalline nature of pure drug into the amorphous form as affirmed by DSC and PXRD result facilitates higher drug release rate over the pure drug ${ }^{(26)}$.

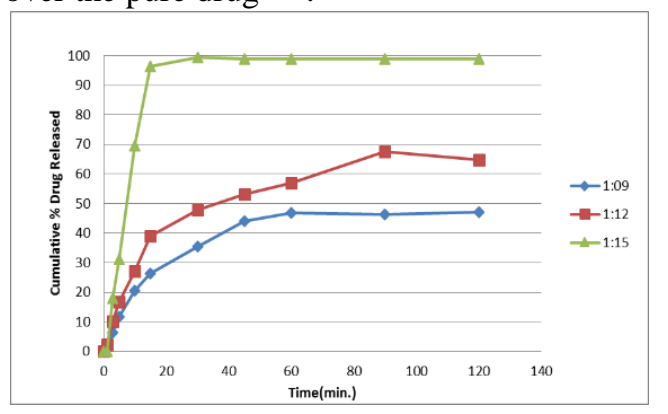

Figure 6. effect of rem: TPGS ratio on cumulative percent drug release profile from rem- solid dispersion prepared by the solvent evaporation method in $0.1 \mathrm{~N} \mathrm{HCl}$ dissolution medium at $37^{\circ} \mathrm{c}$. (results are expressed as mean, $\mathbf{n = 3}$ )

\section{Effect of preparation methods}

The effect of preparation method on the dissolution behavior of REM from prepared drug- solid dispersion was studied.

Figure (7) shows the cumulative percent released of REM from the formulas contain TPGS in a ratio $1: 15$ that prepared by solvent evaporation, fusion and kneading methods, as in SD30, SD33, and SD36.

The results of dissolution of REM for individual samples (pure REM, solvent evaporation, fusion, and kneading methods) were noted, the cumulative percent of REM 
released after 15 minutes was $2.3 \%, 96.3 \%$, $75.3 \%$ and $53.2 \%$, respectively. As shown in Figure (7).

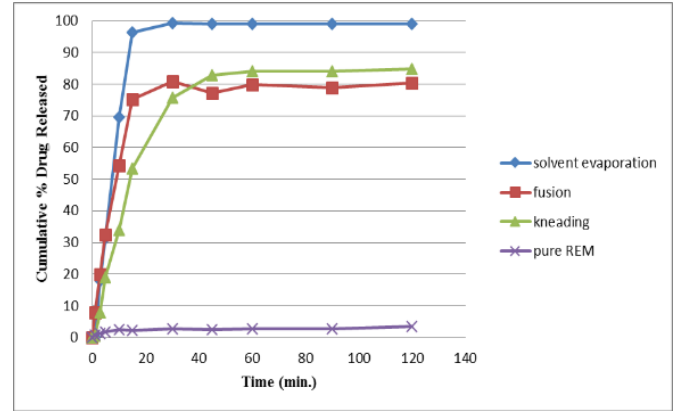

Figure 7. Effect of preparation methods of rem-tpgs solid dispersion at a ratio $(1: 15)$ in $0.1 \mathrm{~N} \mathrm{HCl}$ dissolution medium at $37^{\circ} \mathrm{c}$. (results are expressed as mean, $n=3$ )

The percent of REM release greatly improved with solvent evaporation method than fusion, kneading methods and pure REM as a control, this can be attributed to the fact that solid dispersion prepared by solvent evaporation method result in more uniform and homogenous distribution of REM in hydrophilic TPGS polymer matrix as compared with other methods of preparation ${ }^{(27)}$.

Moreover, when binary system comes in contact with an aqueous dissolution medium, the hydrophilic carrier dissolves and results in precipitation of embedded drug into fine particles, which increase the exposed surface area of the drug for the available dissolution surface ${ }^{(28)}$.

\section{Selection of the best formula}

The selection of the best formula was depended on the solubility study and the cumulative dissolution profile of REM from solid dispersion granules.

It could be concluded that the SD30 which contains REM- TPGS solid dispersion in a ratio 1:15 that prepared by solvent evaporation method was the best formula concerning higher solubility and better dissolution rate percent. Therefore, it was subjected into further in-vitro evaluations study. Evaluation of selected formula

Fourier transforms infrared spectroscopy (FTIR)

The FTIR spectrum for the pure REM, Figure (8) showed the characteristic peaks of the drug at $3276.47 \mathrm{~cm}^{-1}$ which are assigned to the N-H stretching vibration and $2938 \mathrm{~cm}^{-1}$ due to $\mathrm{C}-\mathrm{H}$ stretching of aromatic hydrocarbons, $1725.98 \mathrm{~cm}^{-1}$ due to $\mathrm{C}=\mathrm{O}$ stretching of carboxylic acid and $\mathrm{C}=\mathrm{O}$ of amide stretching at $1643.05 \mathrm{~cm}^{-1}$ and $1338.3 \mathrm{~cm}^{-1}$ due to $\mathrm{C}-\mathrm{N}$ stretching, and $759.82 \mathrm{~cm}^{-1}$ due to $\mathrm{C}-\mathrm{H}$ bending vibrations of aromatic ring ${ }^{(29)}$.

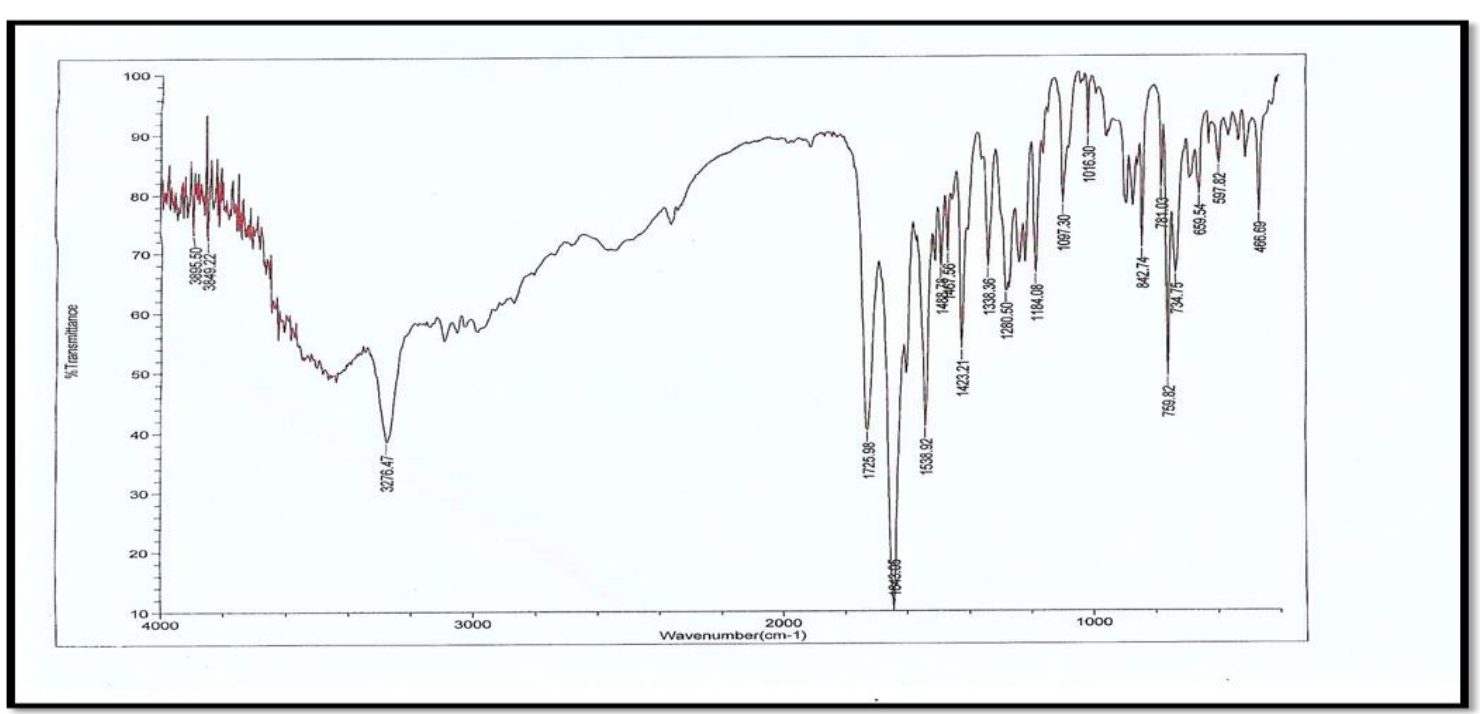

Figure 8. FTIR spectrum of REM

The FTIR spectrum of selected formula (SD30) was shown in Figure (9). It was examined and matched with those of FTIR of REM and TPGS spectrum separately.

The obtained spectra of selected formula
SD30 revealed specific bands at $1644.02 \mathrm{~cm}^{-1}$ and $1736.58 \mathrm{~cm}^{-1}$ for carbonyl groups in amide group and carboxyl functional group respectively, which demonstrated that there is no interaction between REM and TPGS when they incorporated as solid dispersion.

On the other hand, another bands were noticed at $2880.17 \mathrm{~cm}^{-1}$ and weak band at 3210 
$\mathrm{cm}^{-1}$ for both $\mathrm{C}-\mathrm{H}$ stretching for aromatic ring and $\mathrm{N}-\mathrm{H}$ (amine) stretching, respectively, that declare no interaction between REM and TPGS carrier in the SD30 formula ${ }^{(30)}$.

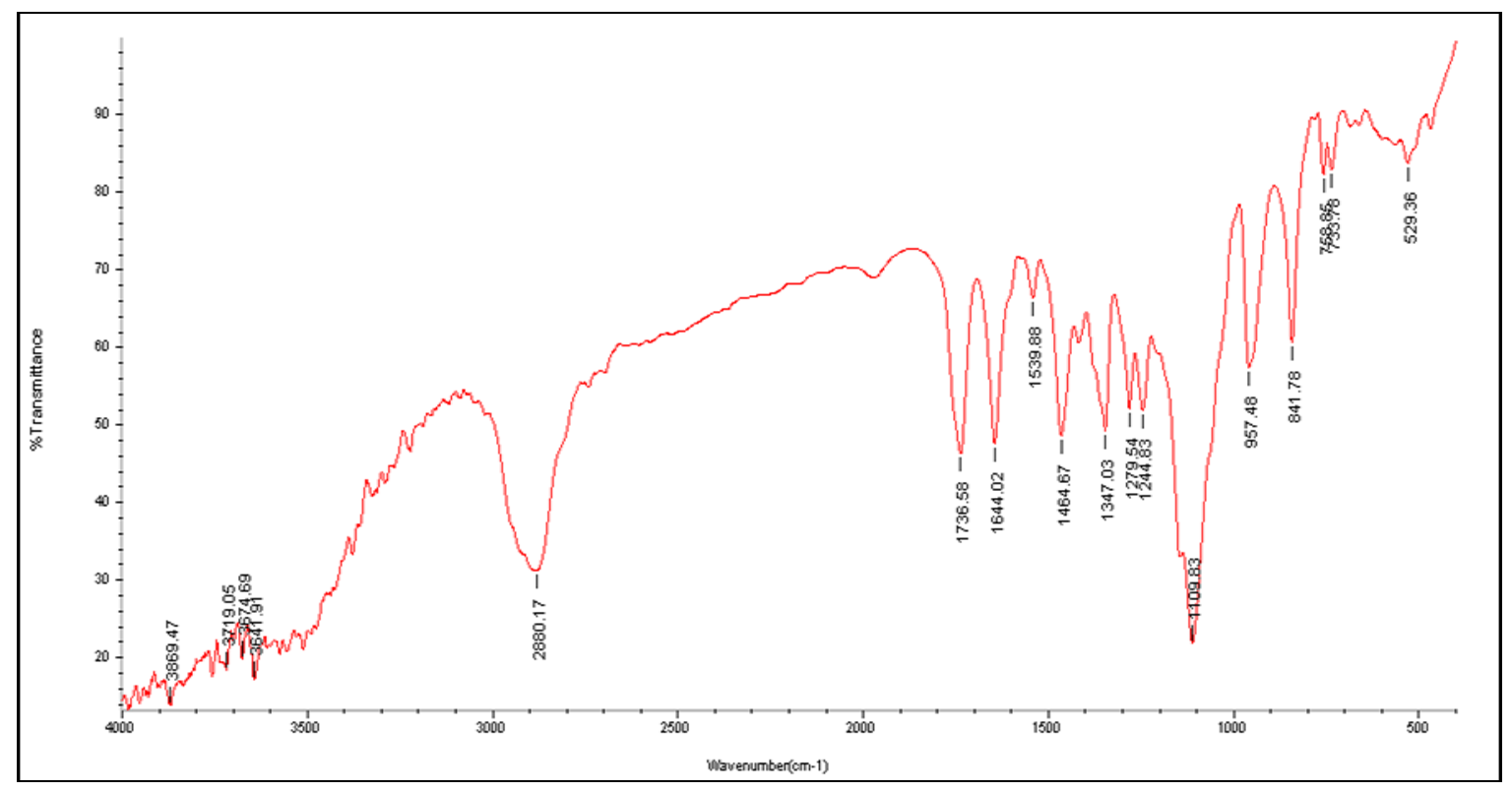

Figure 9. FTIR spectrum of selected formula of rem-TPGS (SD30)

\section{Differential scanning calorimeter (DSC)}

DSC thermo grams of REM and TPGS are presented in Figures (10) and (11) which showed a sharp endothermic peak at $307.06^{\circ} \mathrm{C}$ and $40.68^{\circ} \mathrm{C}$ respectively, they revealed the crystal forms nature of drug and carrier.

Figure (12) represents the DSC thermo gram of REM-TPGS solid dispersion prepared by solvent evaporation method, the presence of single endothermic peak in thermo gram of $\mathrm{SD} 30$ at $39.69^{\circ} \mathrm{C}$ around the polymer melting point.

While the absence of endothermic peak of pure drug at $307.06^{\circ} \mathrm{C}$ in solid dispersion thermo gram could be due to the fact that the drug might transform from its crystalline form to amorphous form in the solid dispersion (SD30) formulation which can be further supported by PXRD ${ }^{(31)}$.

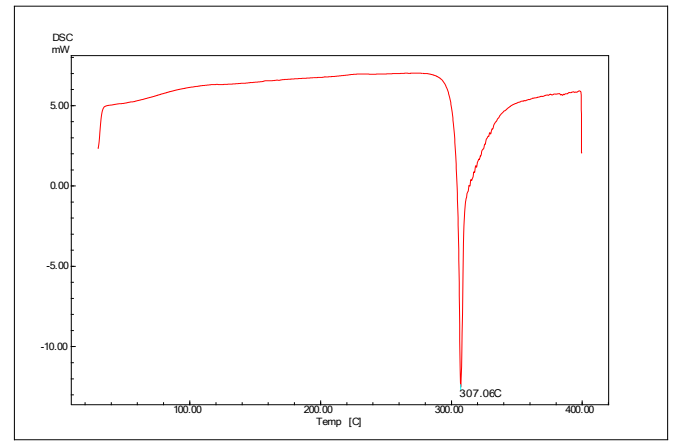

Figure 10. DSC thermogram of REM

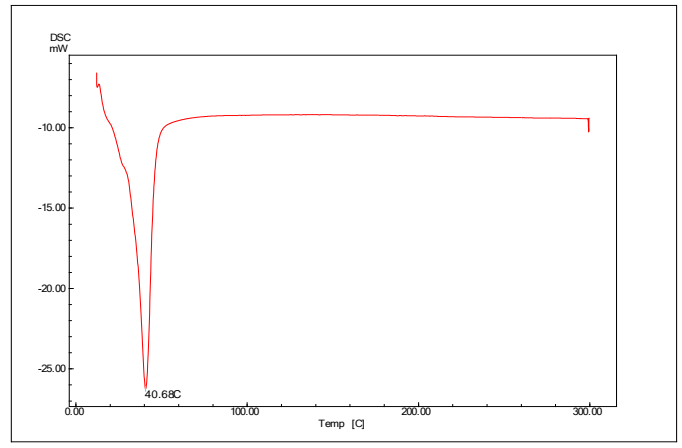

Figure 11. DSC thermogram of TPGS

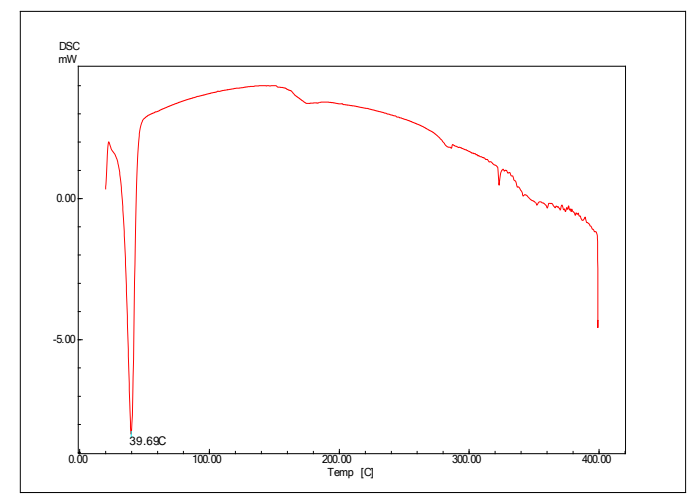

Figure 12. DSC thermogram of selected formula of REM-TPGS (SD 30) 


\section{Powder $x$ - ray diffraction (PXRD)}

The X-ray Diffraction analysis was carried out to confirm the change in the crystalline nature of the drug in solid dispersion and pure form.

The x-ray Diffraction analysis of REM and solid dispersion are given in Figures (13) and (14) respectively. The drug characteristics peaks were observed at $21.7^{\circ}$, and $27.85^{\circ}$ at $2 \theta$ value with intensity 821 , and 736 respectively, the x-ray Diffraction pattern of REM-TPGS solid dispersion (1:15)peaks were observed at $21.7^{\circ}$ at 122 and no characteristic peaks at $27.85^{\circ}$ were obtain. The peak intensities were reduced, indicating the decreased in drug crystal structure, and converted to amorphous one, upon dispersion by solvent evaporation method ${ }^{(32)}$.

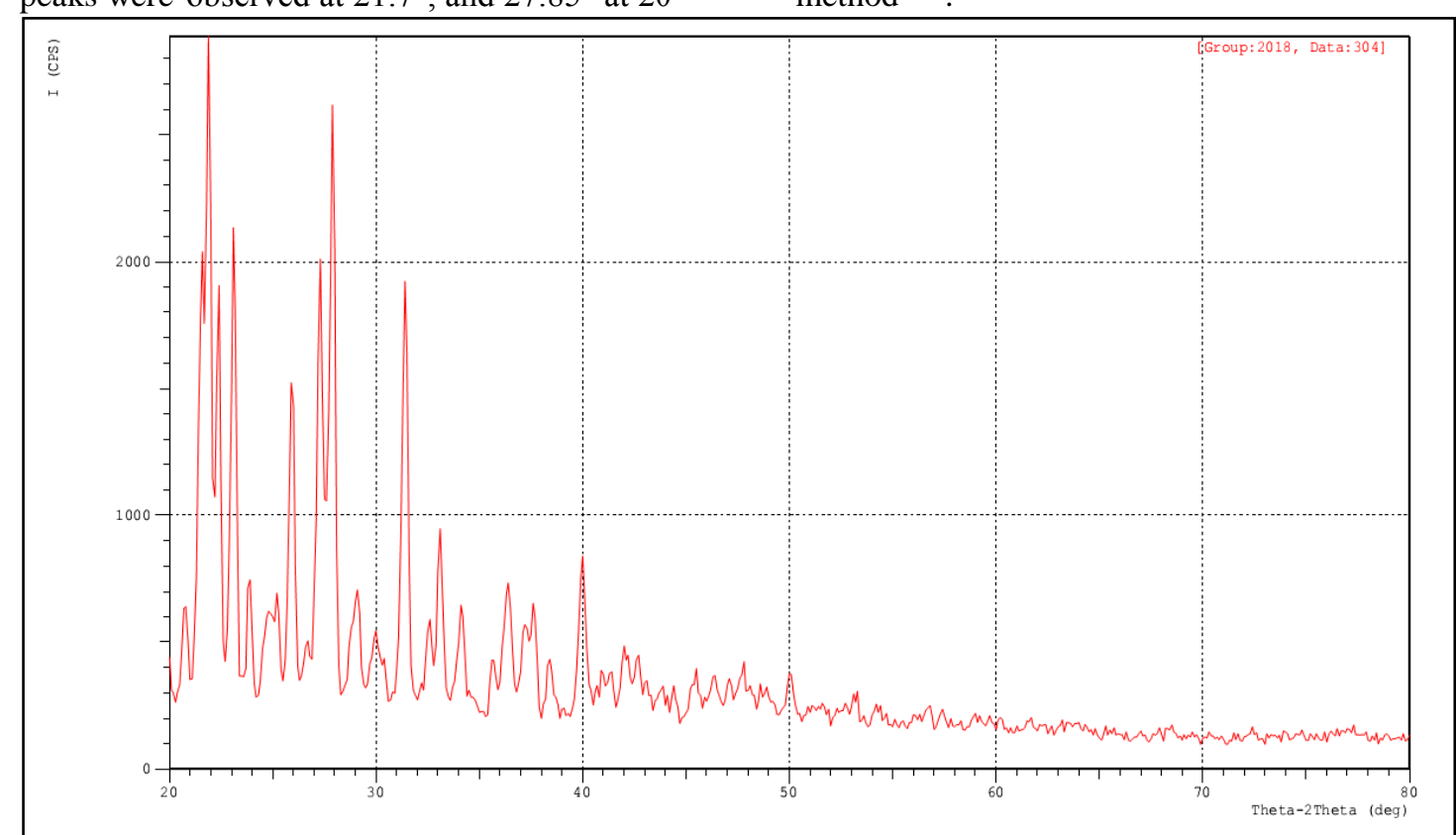

Figure 13. X- ray diffraction (PXRD) pattern of pure REM

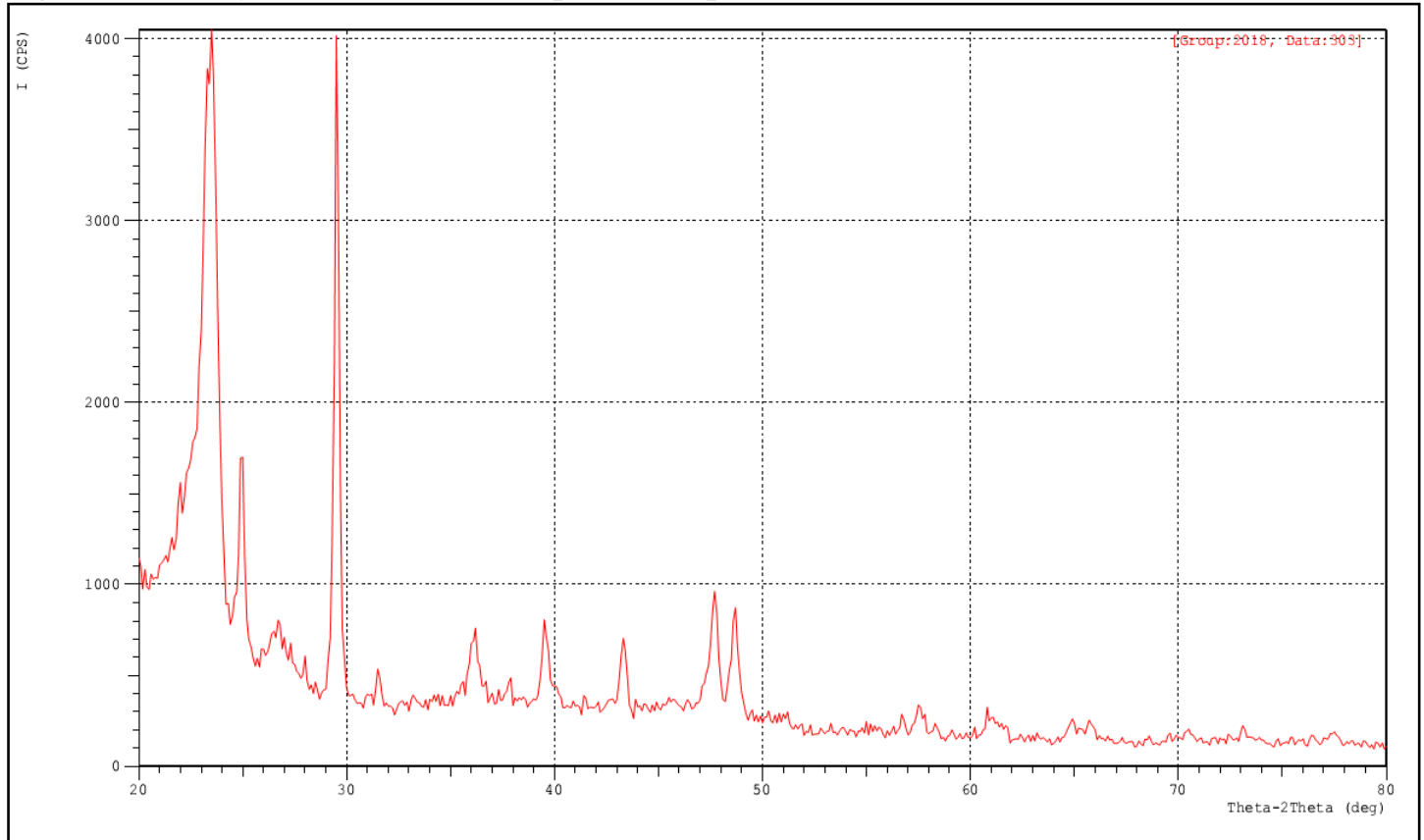

Figure 14. X- ray diffraction (PXRD) pattern of selected formula of REM- TPGS (SD30)

scanning electron microscopy (SEM)

SEM pictures of pure REM and selected formula (SD30) are presented in Figure (15) at 2000 X magnification. The pure REM showed the crystalline appearance, while in
SD30 showed irregular shaped glassy appearance in addition to size reduction and embedment. The smaller particle size as compared with pure drug size lead to great the wetted area, and hence the better the solubility (33). 


\section{Conclusions}

Based on the results obtained from the present study, it can be concluded that the poor solubility of REM (class IV drug) was successfully enhanced using solid dispersion technique and TPGS with (1:15) ratio (SD30) formula appeared to be the best carrier compared to other hydrophilic polymers.

\section{References}

1. Pharmacopoeia J. Society of Japanese Pharmacopoeia. Amended Chapters. 2007;35(35.2):7.

2. Kawano Y, Ishii N, Shimizu Y, Hanawa $\mathrm{T}$. Development and characterization of a suspension containing nanoparticulated rebamipide for a mouth wash for stomatitis. Journal of Pharmaceutical Science and Technology, Japan. 2017;77(2):104-15.

3. Shi Y, Zou M, An Y, Ji Z, Gao P, Cheng G., A potent preparation method combining neutralization with microfluidization for rebamipide nanosuspensions and its in vivo evaluation, Drug Development and Industrial Pharmacy. 2013;39(7):9961004.

4. Pradhan R, Tran T, Choi J, Choi I, Choi H, Yong $\mathrm{C}$ et al. Development of a rebamipide solid dispersion system with improved dissolution and oral bioavailability, Archives of Pharmacal Research. 2014;38(4):522-533.

5. Balasaheb PA, Balaji TE, Avinash BI. Solid dispersions: an overview on solubility enhancement of poorly water soluble drugs, International Journal of Pharma and Bio Sciences. 2014;5(3):7-25.

6. Shamma RN, Basha M. Soluplus: A novel polymeric solubilizer for optimization of carvedilol solid dispersions: formulation design and effect of method of preparation, Powder Technology. 2013;237:406-414.

7. Alves LD, Soares MF, de Albuquerque CT, da Silva ÉR, Vieira AC, Fontes DA, Figueirêdo CB, Sobrinho JL, Neto PJ. Solid dispersion of efavirenz in pvp k-30 by conventional solvent and kneading methods, Carbohydrate Polymers. 2014;104:166-174.

8. Bobe KR, Subrahmanya CR, Suresh S, Gaikwad DT, Patil MD, Khade TS, Gavitre BB, Kulkarni VS, Gaikwad UT., Formulation and evaluation of solid dispersion of atorvatstatin with various carriers, International Journal of Comprehensive. 2011;1: 1-6.

9. Verma S, Rawat A, Kaul M, Saini S., Solid dispersion: a strategy for solubility enhancement, International Journal Of Pharmacy and Technology. 2011;3(2):1062-1099.

10. Dhandapani NV. Dissolution enhancement of raloxifene using water soluble carrier by solid dispersion technique, Asian Journal Of Pharmaceutics. 2018;12(01).

11. Pathak K, Kaushik S. Solubility enhancement of glimperide: development of solid dispersion by solvent melt method, characterization and dosage form development, Pharmaceutical and Biomedical Research. 2017;3(4):1-13.

12. Maruthapillai A, Palanisamy $K$, Sunkara M. Preparation and characterization of rilpivirine solid dispersions with the application of enhanced solubility and dissolution Rate, Beni - Suef University Journal of Basic and Applied Sciences. 2015;4(1):71-109.

13. Soni L, Ansari M, Thakre N, Singh A, Bhowmick M, Rathi J. Development and in-vitro evaluation of furosemide solid dispersion using different water soluble carriers, International Journal. 2017;6(2):2571-2575.

14. Tung NT, Park CW, Oh TO, Kim JY, Ha JM, Rhee YS, Park ES. Formulation of solid dispersion of rebamipide evaluated in a rat model for improved bioavailability and efficacy, Journal of Pharmacy and Pharmacology. 2011;63(12):1539-1547.

15. Bolourchian N, Fashami FM, Foroutan SM. Irbesartan dissolution enhancement using PEG-based solid dispersions: the effect of peg molecular weights, Farmacia. 2017;65(4):537-544.

16. Sharma PK, Sharma PK, Darwhekar GN, Shrivastava B. Formulation and evaluation of solid dispersion of tadalafil, International Journal of Drug Regulatory Affairs. 2018; 6(1):26-34.

17. Barzegar-Jalali $M$, Ghanbarzadeh $S$, Adibkia K, Valizadeh $\mathrm{H}$, Bibak S, Mohammadi G, Siahi-Shadbad MR. Development and characterization of solid dispersion of piroxicam for improvement of dissolution rate using hydrophilic carriers, BioImpacts: BI. 2014;4(3):141148.

18. Shah NU, Kondawar M, Shah R, Shah V. Sustained release of spray-dried combination dry powder inhaler formulation for pulmonary delivery, Asian Journal of Pharmaceutical and Clinical Research. 2011; 4(4):112-118.

19. Gupta R, Mishra AK, Pathak AK. Modification in the approach of developing solid dispersed particles for 
enhanced dissolution, pharmaceutical methods. $2017 ; 8(2)$ : 108-114.

20. The United State Pharmacopeia (USP) 30, NF28. Convention Inc. Rockville, MD. 2010; General test and assays.

21. Sarangi M, Singh N. A comparative study of solubility enhancement of aceclofenac by solid dispersion technique using several polymers, Journal of Applied Pharmacy. 2018;10(1).

22. Devireddy SR, Veerareddy PR. Solubility and bioavailability improvement of gliclazide by solid dispersions using novel carriers, International Journal of Drug Delivery. 2013;4(4):455-461.

23. Minhaz MA, Rahman MM, Ahsan MQ, Khalipa AB, Chowdhury MR. Dissolution enhancement of poorly soluble drug by solvent evaporation method using hydrophilic polymer: a solid dispersion technique, International Journal of Pharmaceutical and Life Sciences. 2012;1(2):1-18.

24. Ha ES, Choo GH, Baek IH, Kim MS. Formulation, characterization, and in vivo evaluation of celecoxib-pvp solid dispersion nanoparticles using supercritical antisolvent process, Molecules. 2014;19(12):20325-20339.

25. Mu L, Feng SS. Vitamin E TPGS used as emulsifier in the solvent evaporation/extraction technique for fabrication of polymeric nanospheres for controlled release of paclitaxel, Journal of Controlled Release. 2002;80(1-3):129144.

26. Dangre PV, Godbole MD, Ingale PV, Mahapatra DK. Improved dissolution and bioavailability of eprosartan mesylate formulated as solid dispersions using conventional methods, Indian Journal of Pharmaceutical Education and Research. 2016;50(3):S209-217.
27. Yadav B, Tanwar YS. Development, characterization and in vitro evaluation of flurbiprofen solid dispersions using polyethylene glycols as carrier, Journal of Applied Pharmaceutical Science. 2016;6(4):60-66.

28. Afifi S. Solid dispersion approach improving dissolution rate of stiripentol: a novel antiepileptic drug, Iranian Journal of Pharmaceutical Research: IJPR. 2015;14(4):1001-1014.

29. . Kanteepan P, Bhikshapathi DV. Design and evaluation of microspheres loaded with rebamipide , Indo American Journal of Pharmaceutical Sciences. 2018;5(2):952-961.

30. Wu Y, Chu Q, Tan S, Zhuang X, Bao Y, Wu T, Zhang Z. D-A-Tocopherol polyethylene glycol succinate-based derivative nanoparticles as a novel carrier for paclitaxel delivery, International Journal of Nanomedicine. 2015;10:52195235.

31. Wendelboe J, Knopp M, Khan F, Chourak $\mathrm{N}$, Rades T, Holm R. Importance of in vitro dissolution conditions for the in vivo predictability of an amorphous solid dispersion containing a ph-sensitive carrier, International Journal of Pharmaceutics. 2017;531(1):324-331.

32. Sathali AA, Jayalakshmi J. Enhancement of solubility and dissolution rate of olmesartan medoxomil by solid dispersion technique, Journal of Current Chemical and Pharmaceutical Sciences 2013;3(2):123-134.

33. Ansari MT, Hussain A, Nadeem S, Majeed H, Saeed-Ul-Hassan S, Tariq I, Mahmood Q, Khan AK, Murtaza G. Preparation and characterization of solid dispersions of artemether by freeze-dried method, BioMed Research International. 2015;2015:1-11. 